\title{
REDEFINIENDO EL CONCEPTO DE PROFESIÓN HABITUAL. SU ESPECIAL INCIDENCIA EN LA CALIFICACIÓN DE INCAPACIDAD PERMANENTE EN EL GRADO DE TOTAL
}

\author{
Javier León Iglesias \\ Abogado. Doctor en Medicina
}

\begin{abstract}
A la espera del desarrollo reglamentario de la Ley General de la Seguridad Social, que conferirá una mayor seguridad jurídica a la tramitación de los expedientes de incapacidad permanente -en especial en lo relativo al grado de total y a la profesión habitual, a la que aquél va anudado-, ha sido la jurisprudencia, influida por la legislación de Prevención de Riesgos Laborales, la encargada de diferenciar este último concepto de los de grupo profesional y puesto de trabajo, obligando así a las reubicaciones laborales del trabajador, en puestos acordes con sus limitaciones, que deben haberse intentado previamente a la declaración incapacitante por parte del INSS, o, en determinados supuestos -los previstos en los Convenios Colectivos-, a posteriori, con el posible quebranto que esto último puede suponer para la naturaleza jurídica de la prestación permanente.

Until the General Social Security Act (LGSS) develops its regulations, which will confer greater legal certainty to the claimants of permanent disability-especially in those cases where the degree of permanent disability is total, and in the determination of the usual occupation, which is a key factor in the process of determining eligibility for it- the distinction between the concepts of usual occupation, professional category and job title has been made following case law, taking into account existing legislation on Prevention of Occupational Hazards. Because of this situation, workers claiming permanent disability must be reassigned to other positions suitable for their capacities before the disability award is made by the INSS, occasionally after the notification, which may harm the legal standing of the benefits granted.
\end{abstract}

IUSLabor 1/2021, ISSN 1699-2938, p. 125-142

DOI. 10.31009/IUSLabor.2021.i01.05

Fecha envío: 29.11.2020 | Fecha aceptación: 25.1.2021

Title: Redefining the concept of usual occupation: the role it plays in determining eligibility for total permanent disability 
Palabras clave: incapacidad permanente total, profesión habitual, movilidad funcional Key words: total permanent disability, usual occupation, job-to-job mobility

\section{Sumario}

1. Introducción

2. A vueltas con la profesión habitual

3. Propuestas de la Administración prestacional

4. Vicisitudes en la doctrina de la movilidad funcional, a la vista de las normativas de Seguridad Social y de Prevención de Riesgos Laborales

5. El problema de las reubicaciones

6. Conclusiones

7. Bibliografía 


\section{Introducción}

Aunque viene de lejos la intencionalidad del legislador de dotar de un contenido más exhaustivo y, a la postre, una mayor seguridad jurídica a los grados de incapacidad permanente, en su modalidad contributiva, a los efectos de redefinir los conceptos de enfermedad y capacidad de trabajo, hemos tenido que esperar hasta la publicación del actual Real Decreto-legislativo 8/2015, de 30 de octubre, por el que se aprueba el Texto Refundido de la Ley General de la Seguridad Social ${ }^{1}$-en adelante TRLGSS, que pretendía unificar la abundante y dispersa legislación existente hasta aquel momento-, para caer en la cuenta de que las tradicionales definiciones de los grados prestacionales, conllevan unas claras notas de provisionalidad, al incorporarlas ahora en su Disposición Transitoria vigésimo sexta y, a partir de ahí, tenerlas por reproducidas en el artículo 194, a la espera del desarrollo reglamentario a que hace mención el apartado $3^{\circ}$ de dicho precepto.

Tres cuestiones son, pues, las que han de configurar-se escuchan voces que aseguran que nunca verán la luz-, la nueva regulación legal:

a) Una lista de enfermedades, causantes de unas concretas repercusiones funcionales en el presunto incapaz -esto último se da por sobreentendido, por su relevancia jurisprudencial-, quizá a semejanza del Disability evaluation under social security norteamericano, cuya aplicación no ha estado exenta de polémicas, por su excesivo rigor regulatorio, que impide la valoración de los nuevos procesos de los que informa la ciencia médica. Podrá instaurarse un modelo de lista cerrada, como las ya existentes en materia de enfermedades profesionales o lesiones permanentes no invalidantes, o quizá a través de un sistema de baremos, como los previstos en el Real Decreto 1971/1999, de 23 de diciembre, de procedimiento para el reconocimiento, declaración y calificación del grado de minusvalía ${ }^{2}$, hoy denominada discapacidad, y anudada a la prestación no contributiva de invalidez, con vistas a dotar de la ansiada coherencia interna a la acción protectora de nuestro sistema público de Seguridad Social.

b) Un sistema capaz de determinar la capacidad laboral residual del asegurado, que se intuye de todo punto novedoso, a la vista que se traslada, también, a la Disposición Transitoria de referencia, el término jurídico de "profesión habitual", que viene configurando los grados de incapacidad permanente parcial y total. Y es que ha sido muy abundante la doctrina jurisprudencial que se ha ido construyendo sobre la profesión habitual, especialmente en la última década, y centrada en el ámbito de incapacitación total, en el cual acotamos nuestro estudio, y que bien podría constituir la antesala de la

\footnotetext{
${ }^{1}$ BOE de 31 octubre de 2015, núm. 261.

${ }^{2}$ BOE de 26 de enero de 2000, núm. 22.
} 
futura regulación legal. c) Múltiples controversias se han ido suscitando, también, en lo relativo a las eventuales reubicaciones laborales, y los problemas que entraña la calificación de incapacidad permanente, cuando la profesión habitual admite, siquiera de forma teórica, la previa movilidad funcional del trabajador afectado a otros puestos compatibles con su situación patológica. Resulta decisiva, en este último sentido, la regulación que nace en la Ley 31/1995, de 8 de noviembre, de Prevención de Riesgos Laborales $^{3}$-en adelante LPRL-, y que ha incidido inequívocamente en las formas de actuar en este tipo de supuestos.

\section{A vueltas con la profesión habitual}

El tenor provisional del artículo 194, $2^{\circ}$ TRLGSS, respeta la definición original del artículo $11,2^{\circ}$ de la Orden de 15 de abril de 1969, por la que se establecen normas para la aplicación y desarrollo de las prestaciones por invalidez en el régimen general de la Seguridad Social ${ }^{4}$, en lo relativo a que la profesión habitual, en el caso de accidente de trabajo o no laboral, se hará coincidir con la desempeñada al tiempo de sufrirlo. No ocurre lo mismo, en cambio, cuando se refiere a la enfermedad común o profesional, eliminando en la nueva redacción el requisito del lapso temporal de desarrollo profesional, por parte del potencial beneficiario de incapacidad permanente, de dicha profesión habitual durante los doce meses anteriores al inicio de la incapacidad temporal de la que deriva la permanente, y sustituyendo el citado pasaje por la lectura “(...) en caso de enfermedad común o profesional, aquélla a la que el trabajador dedicaba su actividad fundamental durante el período de tiempo, anterior a la iniciación de la incapacidad, que reglamentariamente se determine". Ello nos pone en la pista que el legislador propone dos elementos nuevos para incorporar al término legal, en el caso de las enfermedades: a) obvio: que la prestación permanente no siempre va precedida de un subsidio temporal, problema éste que, en la práctica, se venía solventando consignando como profesión, la desempeñada los doce meses anteriores al hecho causante de la incapacidad permanente -repárese en que ahora se habla de "iniciación de la incapacidad", sin referirse de manera expresa al subsidio temporal o a la pensión permanente-, y b) el que pretende enmendar el problema advertido en la fijación de la profesión habitual, pues la que hasta ahora se recogía en buena parte de los expedientes administrativos de incapacidad permanente, como desempeñada en el mentado período de tiempo, no tenía por qué equivaler a la "real". Parece lógico pensar que influye decisivamente, en la previsible reforma futura, el hecho de que la enfermedad es una entidad dinámica, cuya instauración a efectos previsiblemente definitivos, conforme a las exigencias del artículo 193,1 TRLGSS, puede tardar mucho tiempo desde su debut, habiendo obligado al asegurado a cambiar, por tal motivo patológico, su actividad profesional, e integrándose en otra de naturaleza

\footnotetext{
${ }^{3}$ BOE de 10 de noviembre de 1995, núm. 269.

${ }^{4}$ BOE de 8 de mayo de 1969, núm. 110.
} 
disímil, que era la que desarrollaba durante esos últimos doce meses anteriores a la incapacidad temporal de la que deriva la permanente.

Hace casi dos décadas que la Sala Cuarta del Tribunal Supremo -Sentencia de 9 de diciembre de 2002 ( $\mathrm{R}^{\mathrm{o}}$. 1197/2002) ${ }^{5}$-, era consciente de este vacío legal y construye la doctrina-plenamente vigente hasta la actualidad-en el sentido que "la profesión habitual es la ejercida prolongadamente, y no la residual a cuyo ejercicio ha podido haber conducido la situación invalidante", lo que resulta, también, extrapolable a la contingencia de accidente de trabajo. Es decir, el hecho que fuera la propia enfermedad la que aboca al potencial beneficiario, en un período más próximo al hecho causante, a un nuevo desempeño profesional, en modo alguno hace coincidir este último con el concepto jurídico de profesión habitual, reservado, pues, a la actividad laboral más representativa en la vida laboral del sujeto en cuestión.

El artículo analizado no parece variar, en cambio, la expresión "actividad fundamental", que asocia a la profesión habitual, muy probablemente porque los Tribunales han diseñado un concepto abstracto de su contenido. Hace unos años la Sala de lo Social del Tribunal Supremo repasaba la doctrina al efecto, a través de la resolución de 26 de octubre de 2016 ( $\left.\mathrm{R}^{\mathrm{o}} .1267 / 2015\right)^{6}$, recordando que "la delimitación de profesión habitual, no debe identificarse con la categoría profesional, sino con aquellos cometidos que el trabajador esté cualificado para realizar y a los que la empresa le haya destinado o pueda destinarle en movilidad funcional, sin perjuicio de las exigencias de titulación académica o de pertenencia a un grupo profesional”, por lo que -se añade desde la Sala de lo Social del Tribunal andaluz con sede en Málaga, por Sentencia de 11 de julio de 2018 ( $\mathrm{R}^{\mathbf{o}}$. 384/2018) ${ }^{78}$-, "no cabe identificar, pues, profesión habitual con puesto de trabajo habitual ni con categoría, toda vez que lo que se quiere atender no es la específica incidencia que van a tener las secuelas en el concreto empleo que tiene el trabajador, sino algo de mayor significado, dado que normalmente se desempeña una sola a lo largo de la misma, por lo que si ésta se trunca por razón de enfermedad o accidente, la incidencia que la causa es de una magnitud mucho mayor a la que deriva de la concreta pérdida de un especifico empleo".

Ello resulta todavía más evidente cuando nos encontramos en el marco del régimen especial de trabajadores autónomos, en el que, a modo de ejemplo, la profesión habitual incluye "todas aquellas funciones que se corresponden con la dirección del establecimiento y las propias de otros cometidos, con diferentes requerimientos

\footnotetext{
${ }^{5}$ EDJ 2002/61284.

${ }^{6}$ EDJ 2016/202729.

${ }^{7}$ EDJ 2018/609707.
} 
funcionales a los anteriores, como serían las de camarera o cocinera" -STSJ de Cataluña, de 14 de diciembre de 2018 ( $\mathrm{R}^{\circ}$. 5746/2018, Sala de lo Social $)^{9}-$.

Se advierte así, en el caso de los autónomos, una mayor exigencia probatoria, pues "los requisitos en materia de incapacidad, deben ser exigidos con mayor rigurosidad, al no estar sometido el trabajador a la disciplina, órdenes y organización de un patrón, pudiendo organizar libremente su trabajo y delegar las funciones más duras" -entre otras, STSJ de Madrid, de 18 de mayo de 2000 (R'. 5446/1999, Sala de lo Social) ${ }^{109}$-.

Especial detenimiento merecen, también, los centros especiales de empleo, en relación a los cuales no cabe hacer una generalización tal, que permita pensar que una persona con discapacidad no va a poder ser declarada afecta de incapacidad permanente total, mientras exista una actividad profesional susceptible de poder ser realizada en este régimen de empleo protegido. La solución contraria es la que viene adoptándose desde la gestora Instituto Nacional de la Seguridad Social -en lo sucesivo, INSS-, es decir, la de restar relevancia a la concreta modalidad profesional que venía desarrollando el trabajador con discapacidad, confiriéndosela, en cambio, al centro especial de empleo donde venía presentando servicios, criterio éste que viene corrigiéndose judicialmente de manera habitual -entre otras, STSJ del País Vasco, de 2-5-2006 (Ro. 112/2006, Sala de lo Social) ${ }^{11}$, STSJ de Aragón, de 13-11-2013 ( $\mathrm{R}^{\circ}$. 515/2013, Sala de lo Social) ${ }^{12}$ y STSJ de Cataluña, de 16-5-2019 (Rº $807 / 2019$, Sala de lo Social $)^{13}$-.

De todo lo hasta ahora expuesto se colige que a) no cabe identificar profesión habitual con grupo profesional, y b) que la movilidad del asegurado en el desarrollo de puestos de trabajo incluidos en aquélla -lo que descartaría el resultado incapacitante en el grado de total, lo que venimos observando en la forma de resolver múltiples supuestos, tanto en la vía administrativa como en la judicial-, solo tendría como límites, la titulación o el grupo profesional de encuadramiento.

Parece, pues, claro, por ejemplo, que un cajero de supermercado, encuadrado habitualmente en el grupo de cotización 7, correspondiente a los auxiliares administrativos, no siempre contaría con las capacidades profesionales para realizar trabajos de corte administrativo, si no dispone de la capacidad formativa para ello. De ahí la disyuntiva entre titulación y grupo profesional, impuesta jurisprudencialmente.

\footnotetext{
${ }^{9}$ EDJ 2018/720477.

${ }^{10}$ EDJ 2000/52454.

${ }^{11}$ EDJ 2006/388081.

${ }^{12}$ EDJ $2013 / 263340$.

${ }^{13}$ EDJ 2019/620146.
} 
Este criterio, compartido por parte de la doctrina ${ }^{14}$, genera duda en otros autores ${ }^{15}$, al advertir, no sin matices, que la redacción actual del artículo 22 del Real Decretolegislativo 2/2015, de 23 de octubre, por el que se aprueba el texto refundido de la Ley del Estatuto de los Trabajadores ${ }^{16}$, redefiniendo la clasificación profesional por grupos, incrementa las facultades organizativas del empresario, ampliando los límites de la movilidad funcional y, por ende, con clara repercusión en la calificación de la incapacidad permanente.

Albert EMBUENA ${ }^{17}$, en cambio, en su trabajo monográfico sobre incapacidad permanente contributiva, parte de que nos encontramos ante unos conceptos legales indefinidos, tanto en el aspecto legal como jurisprudencial, lo que genera -asegurainseguridad jurídica, pues da lugar a una interpretación, por parte de los órganos judiciales, de lo que debe constituir la profesión habitual del demandante. Propone así un sistema centrado en el puesto de trabajo - "el que el trabajador realiza día tras día"- a acreditar con pruebas testificales, periciales, documentales ergonómicas o basadas en la aportación de profesiogramas.

Hemos de destacar, finalmente, que esta doctrina de la movilidad funcional, que se abordará en profundidad más tarde, que entronca con el concepto de profesión habitual y que limita, en muchos casos, el acceso a la prestación de incapacidad permanente, se atenúa, en cierta medida, en los supuestos de "segunda actividad". Situación ésta en la que se encuentran aquellos profesionales de las fuerzas y cuerpos de seguridad del Estado y bomberos, que acreditan lesiones que les impiden acometer las tareas de la profesión que conllevan habilidad o esfuerzos físicos, o que entrañan peligrosidad, siendo destinados a la realización de otro tipo de puestos de corte administrativo, de formación, de prevención o de planificación, compatibles con su estado secuelar psicofísico.

La Sala Cuarta del Tribunal Supremo, ha mantenido un criterio uniforme desde antaño en distintas Sentencias (de 27 de abril de $2005-\mathrm{R}^{\circ} .998 / 2004{ }^{18}{ }^{18}, 23$ de febrero de $2006-\mathrm{R}^{\mathrm{o}}$.

14 BARBA MORA, Antonio, "Incapacidad laborales y Seguridad Social”, Cizur Menor, Thomson Aranzadi, 2008, p. 39.

15 ARAGÓN GÓMEZ, Cristina, "La compatibilidad entre el trabajo y la pensión de incapacidad permanente", En: MERCADER UGUINA, Jesús, La compatibilidad de las prestaciones del sistema de Seguridad Social y el trabajo, Valladolid, Lex nova Thomson Reuters, 2013, pp. 114 y 115.

${ }^{16}$ BOE de 24 de octubre de 2015, núm. 255.

${ }^{17}$ Un exhaustivo trabajo diseñado a partir de la experiencia en la tramitación de estos casos en la jurisdicción social, en el que se aboga por que el legislador fije los criterios que deben configurar la profesión habitual, teniendo en cuenta las notas de precarización laboral, inestabilidad, pluriempleo y pluriactividad, ALBERT EMBUENA, Vicente, "La incapacidad permanente contributiva, aspectos sustantivos y procesales", Valencia, Tirant lo Blanch, 2017, pp. 94, 106 y 107.

${ }^{18}$ EDJ 2005/90314. 
$5135 / 2004-{ }^{19}, 10$ de junio de $2008-\mathrm{R}^{\mathrm{o}} 256 / 2007-{ }^{20}$ y 10 de octubre de $2011-\mathrm{R}^{\mathrm{o}}$. $4611 / 2010^{21}-$ ), en el sentido de que, a la hora de determinar la merma funcional, ha de tenerse en cuenta el conjunto de actividades que integran objetivamente la profesión habitual, y no sólo las de la segunda actividad, a la que se vio abocada esa persona, a partir de las lesiones que acreditaba.

El trabajo de María de los Reyes MARTÍNEZ BARROSO ${ }^{22}$, se hace eco de esta doctrina mayoritaria, que entronca con el "concepto clásico de profesión habitual, que no se identifica con unas concretas tareas o labores de un puesto de trabajo, sino con el contenido, más amplio y genérico, de la categoría o, más acorde ahora con las últimas reformas legislativas, el grupo profesional". Cita, no obstante, otros pronunciamientos judiciales favorables a la posibilidad de que este grupo de trabajadores pueda ser declarado en el grado de incapacidad permanente total, si se prueba su imposibilidad para el desempeño de los cometidos de la profesión habitual, lo que no obsta -añade-para que se suspenda la citada prestación, para el supuesto que el beneficiario se acoja a la segunda actividad.

Subyace en el debate jurisprudencial aquí analizado -conforme argumenta la misma autora-, la situación muy ventajosa en la que queda el trabajador al que se asignan funciones de segunda actividad, respecto a otras personas, calificadas en el grado de incapacidad permanente total -que protege la pérdida de ingresos que procedían del desarrollo de la profesión habitual-, y que no tienen garantizado un segundo puesto de trabajo compatible, manteniendo las retribuciones anteriores.

\section{Propuestas de la Administración prestacional}

Dispone el artículo $9^{\circ}$ de la Orden de 18 de enero de 1996, para la aplicación y desarrollo del Real Decreto 1300/1995, de 21 de julio, sobre incapacidades laborales del sistema de la Seguridad Social ${ }^{23}$, que "los servicios de la Dirección Provincial del Instituto Nacional de la Seguridad Social, elaborarán un informe de los antecedentes profesionales, que

\footnotetext{
${ }^{19}$ EDJ 2006/31888.

${ }^{20}$ EDJ 2008/155895.

${ }^{21}$ EDJ 2011/242435.

${ }^{22}$ MARTÍNEZ BARROSO, María de los Reyes, "Influencia de la edad en las relaciones laborales: Acceso al empleo y protección social”, Cizur Menor, Thomson Aranzadi, 2018, pp. 522-531; Se insiste en la relevancia de estos supuestos, "dado el número de trabajadores a que puede afectar (tanto aquéllos que prestan servicios en Administraciones Públicas, como aquellos otros que, en empresas privadas, han regulado la cuestión de la "compatibilidad" en los Convenios Colectivos", cubriéndose, por su parte, con la segunda actividad en el ámbito de los cuerpos de la Policía Nacional y de la Guardia Civil, las necesidades de personal, a la vista de unas políticas cada vez más restrictivas.

${ }^{23}$ BOE de 26 de enero de 1996, núm. 23.
} 
permita conocer la profesión desempeñada en el momento en que se efectúa la evaluación y la formación y aptitudes del interesado, que determinen la capacidad residual, una vez. conocidas las limitaciones anatómicas o funcionales que padezca el afiliado”.

Añade este precepto, además, que "para confeccionar el informe podrán utilizarse, además de las manifestaciones del propio interesado y de las informaciones que constan en los ficheros de la Administración actuante y en el Instituto Nacional de Empleo, las que puedan aportarse por parte de la empresa o empresas donde haya prestado sus servicios el evaluado, previo requerimiento de información formulado a tal efecto".

A pesar de las buenas intenciones del legislador, a día de hoy lo único que podemos afirmar es la mera presencia de tal documental en los expedientes de incapacidad permanente, pues la forma genérica e imprecisa con la que suele redactarse, consignando únicamente la profesión y una mención lacónica a que las tareas derivadas de la misma son "las propias", dista mucho de la utilidad probatoria que se pretendía.

Quizá por ello, el INSS editó su "Guía de valoración profesional"2423, en la que explica que, aun cuando en la actualidad existen diferentes sistemas de valoración de puestos de trabajo, la metodología que utilizan se orienta fundamentalmente a las actividades de prevención o a la valoración desde el punto de vista del diseño ergonómico. El objetivo es claro: orientar el reconocimiento médico y la objetivación de las limitaciones orgánicas y funcionales, de acuerdo con el perfil ocupacional del trabajador, en los expedientes de incapacidad permanente, entre otros. En la descripción que se hace de cada una de las modalidades profesionales, se observan dos elementos: a) identificación de la profesión y b) ocupaciones incluidas. La gestora se adapta, en consecuencia, a las corrientes jurisprudenciales ya citadas, y pretende categorizar el concepto de profesión habitual, desglosando a continuación los puestos que se integran en aquélla, facilitando, así, la valoración de si los solicitantes de la prestación conservan o no capacidad para desempeñar otras ocupaciones (puestos) que configuran la citada profesión.

La relevancia que se atribuye a la citada guía, en la práctica judicial de este tipo de supuestos de incapacidad permanente, depende de la casuística, es decir, en ocasiones nos encontramos que los relatos fácticos de las Sentencias reproducen sus contenidos, mientras en otros casos (v.g. STSJ de Aragón de 19 de febrero de $2018-\mathrm{R}^{\circ}$. 84/2018, Sala de lo Social-) $)^{2524}$, se obvian los mismos, al considerarlos "de carácter general y puramente enunciativo".

\footnotetext{
${ }^{24}$ Guía de valoración profesional, Madrid, Instituto Nacional de la Seguridad Social, 2014.

${ }^{25}$ EDJ 2018/35823.
} 
Por lo demás, la guía aporta una útil cuantificación de los requerimientos laborales predicables de cada tipología profesional que analiza (en valores de 1 al 4 , siendo este último el de mayor exigencia), y se pronuncia, asimismo, sobre los riesgos presentes en el entorno laboral, que se toman en consideración para la resolución de determinados supuestos (STSJ de la Comunidad Valenciana, de 20 de noviembre de $2018-\mathrm{R}^{\mathrm{o}}$. 3382/2017, Sala de lo Social ${ }^{26}$ - y STSJ de Castilla-La Mancha, de 16 de mayo de 2019 $-\mathrm{R}^{\mathrm{o}}$. 596/2018, Sala de lo Social ${ }^{27}$-), en un guiño a la Legislación de Prevención de Riesgos Laborales, cuya trascendencia a los efectos de la calificación de incapacidad permanente total resulta incuestionable, como se analizará a continuación.

\section{Vicisitudes en la doctrina de la movilidad funcional, a la vista de las normativas de Seguridad Social y de Prevención de Riesgos Laborales}

La irrupción en las relaciones jurídico-laborales del principio de acción preventiva, que se extiende a la adaptación de los puestos de trabajo (artículo 15, 1 d) LPRL), ha supuesto un cambio importante en lo que a la movilidad funcional se refiere. Con especial atención a la protección de trabajadores especialmente sensibles a determinados riesgos -cuyo tenor literal de protección se reduce, por cierto, a las personas con discapacidad física, psíquica o sensorial, sin mención expresa a la incapacidad laboral (artículo 25)-, regula, como medida instrumental básica, la denominada vigilancia de la salud, en el marco de la cual los servicios de prevención se erigen en órganos calificadores privados, en orden a determinar si un trabajador resulta apto, no apto o apto con restricciones, para el desarrollo de un concreto puesto de trabajo, atendiendo al binomio lesiones-riesgos específicos.

La cuestión es compleja, por cuanto que entronca con la relevancia que tiene la calificación de no apto, emitida por los servicios de prevención -y que puede dar lugar a la modalidad de despido por ineptitud sobrevenida-, a efectos de la declaración del sujeto evaluado en el grado de incapacidad permanente total.

Resulta clarificadora, en este sentido, la Sentencia dictada por el Tribunal Superior de Justicia de Asturias con fecha de 19 de marzo de $2019-\mathrm{R}^{\circ} .85 / 2019$, Sala de lo Social ${ }^{28}$ en la que se explica que "La ineptitud sobrevenida no se confunde con la situación de incapacidad permanente total; ésta consiste en una pérdida definitiva de la capacidad físico-psíquica del trabajador, que le inhabilita para realizar el conjunto o, al menos, las tareas fundamentales de la profesión habitual; la ineptitud sobrevenida conecta con la pérdida de capacidad con el concreto puesto de trabajo desempeñado, no con el más

\footnotetext{
${ }^{26}$ EDJ 2018/706874.

${ }^{27}$ EDJ 2019/610698.

${ }^{28}$ EDJ 2011/242435.
} 
amplio concepto de profesión habitual; puede haber ineptitud sobrevida sin incapacidad permanente total, pero no al revés, aunque el reconocimiento de esta última constituye una causa extintiva del contrato de trabajo distinta". El Tribunal Supremo reiteraba años antes esta misma doctrina ${ }^{29}$, resumiendo el criterio de la Sala de la siguiente forma: “(...) no significa que las decisiones en materia de calificación de la incapacidad deban depender de las que, en función del estado del trabajador, puedan haberse adoptado en la relación de empleo: el sistema de calificación es independiente de las incidencias que puedan producirse en esa relación”.

La jurisprudencia atribuye así a la profesión habitual, prevista en el TRLGSS, evidentes notas de abstracción versus el ámbito de aplicación mucho más reducido del concepto jurídico de puesto de trabajo, epicentro éste de la normativa de Prevención de Riesgos Laborales. Tal abstracción se traslada a la forma en la que los Equipos de Valoración de Incapacidades consignan, en la práctica, la profesión habitual en sus Dictámenes propuesta de incapacidad permanente ${ }^{30}$.

Por la misma razón, no existe equivalencia entre el tipo legal de incapacidad permanente total analizado -normativa de Seguridad Social-y la ineptitud sobrevenida -que es la consecuencia de la calificación de "no aptitud" para el puesto de trabajo, por parte de los servicios de prevención, con amparo en la LPRL-, y ello sin perjuicio de la atención al caso concreto, según se verá más tarde. Respecto al primero, la jurisprudencia reserva la competencia para la calificación de la incapacidad permanente al INSS, a través de los Equipos de Valoración de Incapacidades, atribuida por la normativa de referencia.

Algunos autores ${ }^{31}$ señalan, entonces, que el grado de incapacidad a exigir en estos supuestos de ineptitud sobrevenida, debe encontrarse en el punto intermedio entre el rendimiento óptimo y el espacio propio de una incapacidad permanente total.

Otros trabajos ${ }^{32}$ van más allá, apuntando, como regla general, a que lo que procede en estos supuestos es el reconocimiento del grado de incapacidad permanente parcial.

\footnotetext{
${ }^{29}$ EDJ 2019/553211.

${ }^{30}$ Al respecto, LEÓN IGLESIAS, Javier, "Seguridad Social. Metodología para el estudio de su acción protectora", Madrid, Tecnos, $1^{\text {a }}$ ed., 2020, p. 88, donde se incluyen los siguientes ejemplos: Si el solicitante de incapacidad permanente "se trata de un pintor de fachadas, se señalará como profesión habitual la de pintor", y "si nos encontramos ante un profesor de Universidad, se recogerá la de Profesor".

${ }^{31}$ GONZÁLEZ DE LA ALEJA, Ramón, "La incapacidad permanente y sus efectos en el contrato de trabajo", Albacete, Editorial Bomarzo, 2006, p. 86.

32 TOSCANI GIMÉNEZ, Daniel, "El régimen de las pensiones de incapacidad permanente: derechos y obligaciones de solicitantes y beneficiarios", Valencia, Tirant lo Blanch, 2012, p. 26.
} 
Esta misma línea jurisprudencial la encontramos en la STSJ de Aragón, de 28 de septiembre de $2018-\mathrm{R}^{\mathrm{o}}$. 462/2018, Sala de lo Social ${ }^{33}$, en la que se confirma la denegación de incapacidad permanente total para la profesión de personal de servicios auxiliares en la administración autonómica, operada por el Juez de instancia, a pesar de que el técnico de prevención había estudiado los riesgos del puesto, concluyendo que no se podía garantizar la protección de la salud de la trabajadora, sin posibilidad, tampoco, de ubicación en otro puesto de trabajo ni cambio de categoría. Esta Sentencia se hace eco, además, de la doctrina del Tribunal Supremo (Sentencia de 28 de septiembre de $2017 \mathrm{R}^{\circ}$. $3978 / 2015$, Sala de lo Social ${ }^{34}-$ ), que se pronuncia sobre una materia conexa con la que ahora nos ocupa; a saber, si la pérdida de la licencia para seguir desempeñando el puesto -en aquel caso los permisos de conducción y consiguiente permiso municipal de conductor de autotaxi-conlleva necesariamente la calificación de la situación invalidante en el grado de total. Recuerda el Alto Tribunal que "la calificación y declaración de la incapacidad permanente compete primero a las entidades gestoras de la Seguridad Social y, después, a los Tribunales”, y que "de asimilarse la privación del permiso de los conductores profesionales a la declaración de incapacidad permanente total, se dejaría ésta en manos, no ya de una instancia administrativa, sino del propio interesado". No veda, no obstante, el acceso a la prestación permanente en todos los casos, toda vez que se indica que tal calificación extramuros al INSS, debe ser ponderada, junto al resto de datos que constan en el expediente administrativo, pero sin concederle valor determinante.

Parece claro, en este sentido, que la declaración de incapacidad permanente viene atribuida en exclusiva al INSS, conforme a lo previsto en el artículo $1^{\circ}, 1$ a) del Real Decreto 1300/1995 de 21 de julio, por el que se desarrolla, en materia de incapacidades laborales del sistema de la Seguridad Social, la Ley 42/1994, de 30 de diciembre, de medidas fiscales, administrativas y de orden social ${ }^{35}$. Más dudoso resulta, sin embargo, lo regulado a través del artículo $2^{\circ}$, apartado $4^{\circ}$, de la misma norma, pues, aun cuando consigna, en la composición de los Equipos de Valoración de Incapacidades, a un experto de seguridad e higiene en el trabajo - de lo que podría colegirse que la inhabilidad para el desempeño del concreto puesto de trabajo, va a ser, al menos, tenida en cuenta a efectos del sentido de la calificación-, acto seguido reduce la integración de este perfil profesional en el Equipo, a aquellos casos en los que existen indicios de incumplimiento de las medidas de seguridad e higiene en el trabajo.

Y todo cuanto antecede, sin perjuicio de la dificultad que entraña, en el ámbito procesal, la acreditación de los contenidos de los reconocimientos de salud y/o pérdidas de

\footnotetext{
${ }^{33}$ EDJ 2018/727054.

${ }^{34}$ EDJ 2017/215973.

${ }^{35}$ BOE de 19 de agosto de 1995, núm. 198.
} 
licencias. Su naturaleza de pruebas preconstituidas exige, en la mayoría de las ocasiones, que hayan de ser ratificadas en la vista oral por los facultativos que las expiden, según se recuerda en la STSJ de las Islas Baleares, de 24 de enero de $2019-\mathrm{R}^{\circ}$. 454/2018, Sala de lo Social ${ }^{36}$.

\section{El problema de las reubicaciones}

Podemos encontrarnos, pues, con supuestos de calificación de no apto, por parte de los servicios de prevención, de los que se deriva implícitamente la obligación empresarial, acudiendo a la normativa de prevención de riesgos laborales, de reubicar al trabajador declarado no apto, en otros puestos compatibles con su estado de salud, de los que integran el término desarrollado jurisprudencialmente de profesión habitual, exigencia legal ésta que restringe el acceso al ámbito de la acción protectora de la Seguridad Social.

En este sentido, se demostró estadísticamente, en el ámbito de la pensión de incapacidad permanente de las patologías acotadas para la investigación ${ }^{37}$, que existía una menor tendencia a la estimación de las prestaciones, cuando la profesión habitual desarrollada era de contenido físico, lo que se explica por el mayor margen de actuación reubicadora que tienen las empresas ante actividades profesionales de carga física versus las modalidades profesionales sedentarias o intelectuales.

Pero puede darse el caso de que el solicitante de prestación no se encuentre en activo laboral en el momento de la calificación de la incapacidad permanente. Si existe la posibilidad, al menos teórica, de poderse llevar cabo la reubicación a un puesto de trabajo compatible, dentro de su profesión habitual, LEÓN IGLESIAS ${ }^{38}$, haciéndose eco de algunas sentencias, traslada la protección por la pérdida del puesto a las prestaciones de desempleo, si es que se reúnen los presupuestos legales de acceso a las mismas.

Cabe la posibilidad también de que, en atención a la casuística para la valoración de los reconocimientos de salud, junto al resto de elementos probatorios de los expedientes -el Tribunal Supremo deja abierta esta vía, conforme se ha expuesto más atrás-, se declare al asegurado afecto de incapacidad permanente total.

\footnotetext{
${ }^{36}$ EDJ 2019/537459.

${ }^{37}$ A este respecto, LEÓN IGLESIAS, Javier, "Búsqueda de nuevos criterios de valoración del menoscabo funcional en los procesos de incapacidad permanente con causa en la Fibromialgia y/o Síndrome de Fatiga crónica. Un enfoque multidisciplinar", Leioa, Universidad del País Vasco, 1ª ed., 2005, pp. 75 у 78, debiendo tomarse los resultados de referencia con cautela, a la vista del tamaño muestral, lo que es, también, extrapolable a aquellos datos que ponían de manifiesto una mayor tendencia a la estimación de los supuestos iniciados por varones, respecto a las mujeres -perspectiva de género incorporada al citado trabajo-.

${ }^{38}$ Op. cit. LEÓN IGLESIAS, Javier, "Seguridad Social. Metodología para el estudio de su acción protectora".
} 
En tal situación prestacional, la situación se complica cuando existe obligación convencional, por parte de la mercantil en la que presta servicios el pensionista, de destinarle a la realización de puesto de trabajo compatible con su situación funcional, como se indica en la STSJ de Andalucía, sede de Sevilla, de 28 de julio de $2016-\mathrm{R}^{\mathbf{o}}$. $2127 / 2015$, Sala de lo Social ${ }^{39}$.

Se trata, como ya se ha anticipado, de un problema que viene debatiéndose desde antaño ${ }^{40}$, al considerarse que se coloca a determinados colectivos en una posición ventajosa respecto al resto de trabajadores, dado que el beneficiario de pensión tendrá, además, derecho a las mismas retribuciones que en el puesto que venía desempeñando anteriormente, contraviniendo así la naturaleza de la prestación permanente, que no es otra que la de sustitución de las rentas dejadas de percibir.

A este respecto, como acertadamente indica José Luís GOÑI SEIN ${ }^{41}$, la sola tutela del Estatuto de los Trabajadores -sin existir amparo en el Convenio Colectivo-, "no establece obligación alguna de mantener la relación laboral, ni de realizar un esfuerzo de adaptación de las condiciones de trabajo a sus nuevas condiciones de aptitud", y, cuando sí que concurre regulación convencional, se da el inconveniente adicional de la reubicación condicionada a la existencia de una vacante adecuada, es decir, ajustada a las características del trabajador con capacidad disminuida, lo que ha generado una casuística judicial no uniforme. La obligación de reubicación se reduciría, pues, a los supuestos en los que las cláusulas de la negociación colectiva, reconocen al trabajador un derecho absoluto a su reubicación -sin la coletilla sobre la existencia de vacantes-. Y ello con la dificultad añadida que supone el hecho de que, en la práctica, no haya claridad en los Convenios, en la forma de definir los grupos profesionales, resultando, por ello, complejo determinar qué es lo que puede o no puede realizar el trabajador al que se reconoce la incapacidad permanente ${ }^{42}$.

\footnotetext{
${ }^{39}$ EDJ 2016/216468.

${ }^{40}$ Op. cit. ARAGÓN GÓMEZ, Cristina, "La compatibilidad entre el trabajo y la pensión de incapacidad permanente"; Op. cit. MARTÍNEZ BARROSO, María de los Reyes, "Influencia de la edad en las relaciones laborales: Acceso al empleo y protección social"; Op. cit. TOSCANI GIMÉNEZ, Daniel, "El régimen de las pensiones de incapacidad permanente: derechos y obligaciones de solicitantes y beneficiarios".

${ }^{41}$ GOÑI SEIN, José Luis, RODRÍGUEZ SANZ DE GALDEANO, Beatriz, “Adaptación y reubicación laboral de trabajadores con limitaciones psicofísicas", Cizur Menor, Thomson Aranzadi, pp. 188, 252 y 254.

${ }^{42}$ Op. cit. MARTÍNEZ BARROSO, María de los Reyes, "Influencia de la edad en las relaciones laborales: Acceso al empleo y protección social"
} 


\section{Conclusiones}

Ante un panorama normativo a la espera de desarrollo reglamentario de larga data, se ha ido construyendo a golpe de jurisprudencia, más que lo que debemos entender por profesión habitual, lo que, de ninguna manera, configura tal concepto: No lo es a) ni el grupo profesional, b) ni el puesto de trabajo, c) ni tampoco, necesariamente, en las contingencias de las enfermedades, la desarrollada de forma más próxima al hecho causante de la incapacidad permanente. Por otra parte, el desarrollo normativo en materia de Prevención de Riesgos Laborales, ha conferido importantes atribuciones calificadoras a los servicios de prevención, pero éstas quedan reducidas a su ámbito competencial, cual es el del análisis del puesto de trabajo, pues la calificación de la incapacidad permanente en el grado de total, con epicentro en el concepto jurídico de profesión habitual, queda reservada en exclusiva -no sin matices- al INSS a través de los Equipos de Valoración de Incapacidades. Habremos de esperar a las futuras -esperemos que no lejanasdescripciones que incorpore, al respecto de la profesión habitual, el TRLGSS, también en lo relativo a la clasificación lesional y funcional, a efectos de incapacidad permanente, quien sabe si en forma de lista cerrada, con sus indeseables efectos ya producidos en otros países.

A juicio de este autor, las eventuales reformas legislativas que, en su caso, se adopten, podrían tomar en consideración, a modo de lege ferenda, los siguientes criterios:

a) Incluir el uso preceptivo, en la instrucción de los expedientes administrativos de incapacidad permanente -también, naturalmente, en la posterior facultad revisora de la Jurisdicción Social-, de unos parámetros definitorios de cada una de las profesiones existentes en nuestro mercado de trabajo, en cuanto a puestos que engloban cada una de ellas, tareas, requerimientos, riesgos laborales, etc. Comoquiera que la jurisprudencia no es unánime a la hora de determinar el alcance probatorio que debe atribuirse a la ya citada Guía de valoración profesional del INSS ${ }^{43}$, quizá por haber sido elaborada, de manera exclusiva, por profesionales de la citada entidad gestora, la solución podría venir de la confección de un nuevo material, consensuado entre los órganos administrativos responsables de la calificación de la incapacidad permanente, la patronal, los sindicatos y las mutuas de accidentes de trabajo y enfermedades profesionales; sin pasar por alto, tampoco, la indudable experiencia que pueden aportar, en una comisión de trabajo de estas características, las correspondientes entidades del tercer sector.

b) Determinar que el órgano de calificación ha de resolver los expedientes de incapacidad permanente en un doble sentido: 1) la incapacidad o no incapacidad del solicitante para

\footnotetext{
${ }^{43}$ Op. cit., Instituto Nacional de la Seguridad Social, "Guía de valoración profesional"
} 
el desempeño de la profesión habitual, a partir de los criterios consensuados a que acabamos de hacer mención, y 2) la incapacidad o no incapacidad del asegurado para el desarrollo del puesto de trabajo habitual. Si se decide en el sentido de la inhabilidad solamente para el concreto puesto, debería obligarse a la empleadora a reubicar al trabajador -en la medida de sus posibilidades materiales u organizativas- en otro puesto acorde con sus limitaciones físicas o psiquiátricas, pudiéndose recabar, para ello, la intervención de la Inspección de Trabajo y Seguridad Social, a los efectos de comprobar la posibilidad real de la mercantil de que se trate, para proceder a la citada movilidad funcional. Si se concluye que no es posible cumplir con tal alternativa, la solución debería venir de la mano de un grado de prestación, a caballo entre el tipo legal de incapacidad permanente parcial y el de total -en parecidos términos a lo que señala parte de la doctrina $^{44}$ - si bien, a juicio de quien suscribe, esta modalidad prestacional debería ser de carácter vitalicio y con una cuantía resultante de aplicar un menor porcentaje a la base reguladora, respecto al previsto para la incapacidad permanente total. Todo ello conllevaría la revocación de las competencias, al respecto, de los servicios de prevención, a menudo cuestionadas por los Tribunales, y generadoras, en muchos casos, de despidos por ineptitud sobrevenida. En otro caso, nos encontraríamos con supuestos injustos, en los que algunos solicitantes (v.g. quienes solicitan la prestación de incapacidad permanente desde la situación de paro involuntario), y que no alcanzan el grado de incapacidad permanente total, por estar únicamente limitados para el desempeño de su puesto de trabajo habitual, quedarían desprotegidos, tanto por no poder acceder a las prestaciones de desempleo, como por no estar en disposición de ser reubicados laboralmente.

c) Evitar el privilegio que supone, en la práctica, para determinados grupos de trabajadores, la compatibilidad de la incapacidad permanente total que les ha sido reconocida, con el salario íntegro correspondiente a un nuevo puesto compatible con sus limitaciones; y ello como derecho derivado del Convenio Colectivo de aplicación que prevé la reubicación laboral. Entiende este autor que ello se podría conseguir limitando la duración de la jornada laboral del sujeto en cuestión en el nuevo puesto, hasta alcanzar el montante económico que dejaría de percibir con la incapacidad permanente total: del $55 \%$ al $100 \%$ de su base reguladora. Este criterio sería extrapolable a los supuestos en los que no existe tal obligación convencional, pero en los que el beneficiario compatibiliza su pensión con el desempeño de profesión disímil en otra empresa.

\footnotetext{
${ }^{44}$ Op. cit., GONZÁLEZ DE LA ALEJA, Ramón, "La incapacidad permanente y sus efectos en el contrato de trabajo"
} 
La solución normativa, de cualquier forma, no es fácil, pues, como muy acertadamente señalaban Remedios ROQUETA BUJ y Celia FERNÁNDEZ PRATS ${ }^{45}$, "la prestación de incapacidad permanente presenta una regulación sumamente compleja, oscura y cambiante", partiendo del hecho de que "las normas reguladoras de la prestación se encuentran excesivamente fragmentadas", y convirtiéndose éste en un "tema especialmente litigioso, conflictivo y casuístico".

\section{Bibliografía}

ALBERT EMBUENA, Vicente, "La incapacidad permanente contributiva, aspectos sustantivos y procesales", Valencia, Tirant lo Blanch, 2017.

ARAGÓN GÓMEZ, Cristina, "La compatibilidad entre el trabajo y la pensión de Incapacidad Permanente", En: MERCADER UGUINA, Jesús, La compatibilidad de las prestaciones del sistema de Seguridad Social y el trabajo, Valladolid, Lex nova Thomson Reuters, 2013.

BARBA MORA, Antonio, "Incapacidad laborales y Seguridad Social”, Cizur Menor, Thomson Aranzadi, 2008.

GONZÁLEZ DE LA ALEJA, Ramón, "La incapacidad permanente y sus efectos en el contrato de trabajo", Albacete, Editorial Bomarzo, 2006.

GOÑI SEIN, José Luis y RODRÍGUEZ SANZ DE GALDEANO, Beatriz, "Adaptación y reubicación laboral de trabajadores con limitaciones psicofísicas", Cizur menor, Thomson Aranzadi, 2015.

Guía de valoración profesional, Madrid, Instituto Nacional de la Seguridad Social, 2014.

LEÓN IGLESIAS, Javier, "Seguridad Social. Metodología para el estudio de su acción protectora", Madrid, Tecnos, $1^{\text {a }}$ ed., 2020.

LEÓN IGLESIAS, Javier, "Búsqueda de nuevos criterios de valoración del menoscabo funcional en los procesos de incapacidad permanente con causa en la Fibromialgia y/o Síndrome de Fatiga crónica. Un enfoque multidisciplinar", Leioa, Universidad del País Vasco, $1^{\mathrm{a}}$ ed., 2005.

\footnotetext{
${ }^{45}$ ROQUETA BUJ, Remedios, FERNÁNDEZ PRATS, Celia, "La incapacidad para trabajar", Madrid, Wolters Kluwer España, 2014, Sinopsis.
} 
MARTÍNEZ BARROSO, María de los Reyes, "Influencia de la edad en las relaciones laborales: Acceso al empleo y protección social”, Cizur Menor, Thomson Aranzadi, 2018.

ROQUETA BUJ, Remedios y FERNÁNDEZ PRATS, Celia, "La incapacidad para trabajar", Madrid, Wolters Kluwer España, 2014.

TOSCANI GIMÉNEZ, Daniel, "El régimen de las pensiones de incapacidad permanente: derechos y obligaciones de solicitantes y beneficiarios" Valencia, Tirant lo Blanch, 2012. 